\title{
UNMANNED AERIAL VEHICLE APPLICATIONS OF 3D MODELLING, VISUALIZATION AND PARAMETER CALCULATIONS
}

\author{
Vinit Lambey ${ }^{1}$, A D Prasad ${ }^{1 *}$ \\ ${ }^{1}$ Department of Civil Engineering, National Institute of Technology Raipur, Raipur, India - (vinitlambey39, \\ adprasadiit)@gmail.com
}

Commission V, SS: Emerging Trends in Remote Sensing

KEY WORDS: UAV, Remote Sensing, 3D modelling, EDM

\begin{abstract}
:
Photogrammetric surveying with the use of Unmanned Aerial Vehicles (UAV) have gained vast popularity in short span. UAV have the potential to provide imagery at an extraordinary spatial and temporal resolution when coupled with remote sensing. Currently, UAV platforms are fastest and easiest source of data for mapping and 3D modelling. It is to be considered as a low-cost substitute to the traditional airborne photogrammetry. In the present study, UAV applications are explored in terms of 3D modelling, visualization and parameter calculations. National Institute of Technology Raipur, Raipur is chosen as study area and high resolution images are acquired from the UAV with $85 \%$ overlap. 3D model is processed through the point cloud generated for the UAV images. The results are compared with traditional methods for validation. The average accuracy obtained for elevation points and area is $97.99 \%$ and $97.75 \%$. The study proves that UAV based surveying is an economical alternative in terms of money, time and resources, when compared to the classical aerial photogrammetry methods.
\end{abstract}

\section{INTRODUCTION}

An unmanned aerial vehicle (UAV) is a category of aircraft that drives without a human pilot on-board. UAVs can also be abbreviated as Uninhabited Air Vehicles (Sanna and Pralio, 2005). Previously, UAV systems and platforms were mainly used for military applications. At present UAV have become a common platform for data acquisition in the field of geomatics. UAV photogrammetry is definitely a low-cost substitute to the traditional airborne photogrammetry for detailed 3D modelling of ground information (Colomina et al., 2008 and Eisenbeiss 2009). Photogrammetric products primarily DSM and orthoimages from UAV-based aerial images are offered by the private sectors. When compared to the traditional aircrafts, these flying platforms comes in variable dimensions having less weight and high ground resolution.

\subsection{UAV Platforms}

Mainly, UAVs are classified as multi rotor, fixed wing or helicopter types. Fig. 1 shows the different types of UAV platforms. A basic flight of any UAV totally depends on the flight control system. These system mainly includes an inertial measurement unit (IMU) which is linked to a processor through which power distribution is managed in the motors thereby stabilizing the flight. In addition to it, magnetometer, barometer as well as a Global Positioning System (GPS) is also attached to the control system.

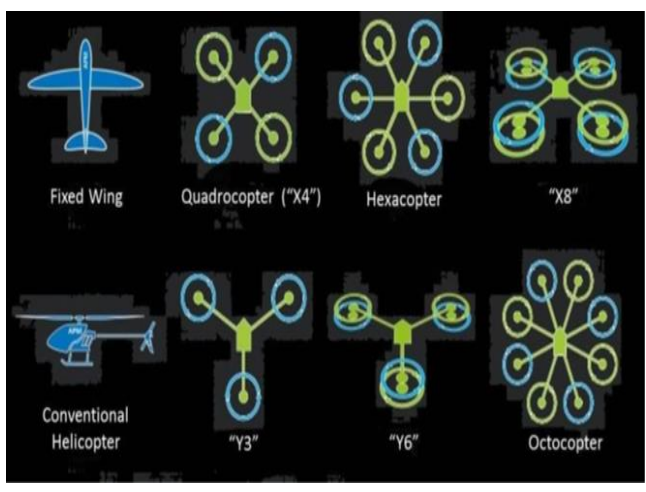

Figure.1. General flow chart for 3D mapping using UAV (Source: http://planner.adrupilot.com)

\subsection{Basic Flight Planning for UAV}

Flight planning of any unmanned aerial vehicle primarily depends on the factors such as the focal length, camera resolution, flying height and ground resolution required. For obtaining high resolution images, the Ground Sampling Distance (GSD) should be least. GSD is the measurement of a square on the ground covered by single pixel (p) in the image and is a function of the camera resolution, the focal length ( $f$ ) and the flying height $(\mathrm{H})$ which is the distance between camera and ground. GSD can be calculated as shown in eqn. (1)

$$
\frac{G S D}{p}=\frac{H}{f}
$$

In aerial mapping done for obtaining 3D models, it is necessary to capture the images with sufficient stereo overlap (60-80\%). Depending on the mission specifications, environmental conditions and type of UAV platform, flight can be manual, assisted or autonomous. 


\subsection{Data Acquisition and Processing}

The basic requirement for a UAV based aerial survey is flight planning and Ground Control Points (GCP) measurement for geo-referencing purposes. The acquired images are mosaicked for further processing (Neitzel and Klonowski, 2011). Digital Surface Model (DSM) is generated by initially accomplishment of camera calibration and image triangulation. The subsequent outcomes are finally used for the production of ortho-images, 3D modelling applications. Fig. 2 shows the general flow chart for 3D mapping using UAV.

\begin{tabular}{|c|c|c|}
\hline & - Planning & \multirow{2}{*}{ - ACQUISITION } \\
\hline & - UAV Operation & \\
\hline & - Orientation \& Geo-referencing & \multirow{2}{*}{ - NORMALISATION } \\
\hline & - Calibration & \\
\hline & - Orthophoto \& DEM Generation & \multirow{2}{*}{ - INTERPRETATION } \\
\hline $\mathbf{E}$ & - GIS Analysis \& Remote Sensing & \\
\hline
\end{tabular}

Figure.2. General flow chart for 3D mapping using UAV (Khaula and Abdelgadir, 2017)

\subsection{Camera Calibration and Image Orientation}

Camera calibration and image orientation are prerequisites for construction of a 3D image. It requires the generation of tie points followed by a bundle adjustment which is a non-linear optimization technique to minimize a suitable cost work (Brown, 1976; Triggs et al., 2000; Gruen and Beyer, 2001). The all above parameters can be obtained using the commercial softwares available. These software needs the availability of GPS data for extraction of tie points and for direct goereferencing of the acquired images. In applications where rapid data acquisition is required and low quality images are acceptable e.g. for disaster prone area, the accuracy of GPS observation is sufficient (Pfeifer et al., 2009 and Zhou, 2009). The basic objective is to obtain a good quality of images in order to calculate the coordinates of the objects and 3D shape of image.

\subsection{Surface reconstruction and Orthoimage generation}

After the orientation of the images, the 3D modelling is done in step by step process which includes surface measurement, feature extraction and orthophoto generation. As the camera orientation parameters are known, any part of the image can be recreated with the help of automated dense image matching technique. The output is a thin or a dense point cloud, which describes the feature of the shape which has been surveyed. Dense point clouds are preferred for surface reconstruction while sparse clouds are preferred when modelling buildings (manmade structures). In order to attain accurate ortho-rectification and complete exclusion of distortions, dense point cloud is necessary to generate orthoimages (Neitzel and Klonowski, 2011).

\section{STUDY AREA AND METHODOLOGY}

National Institute of Technology Raipur, Raipur is chosen as study area for this study (Fig.3). The campus spreads in an area of approximately 100 acres. The study has been carried out on the main building of the campus along the stretch of $298.16 \mathrm{~m}$.

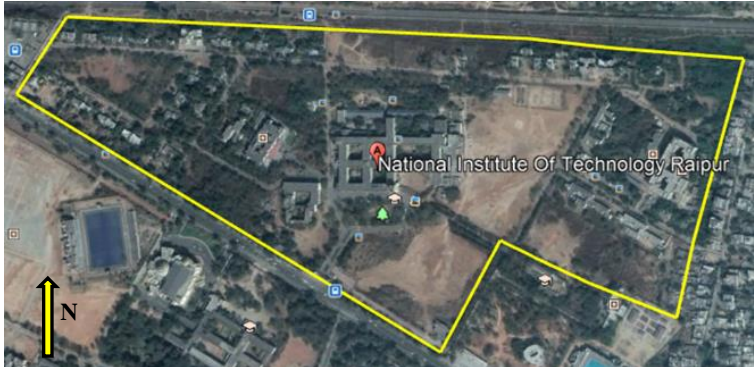

Figure.3. Study area

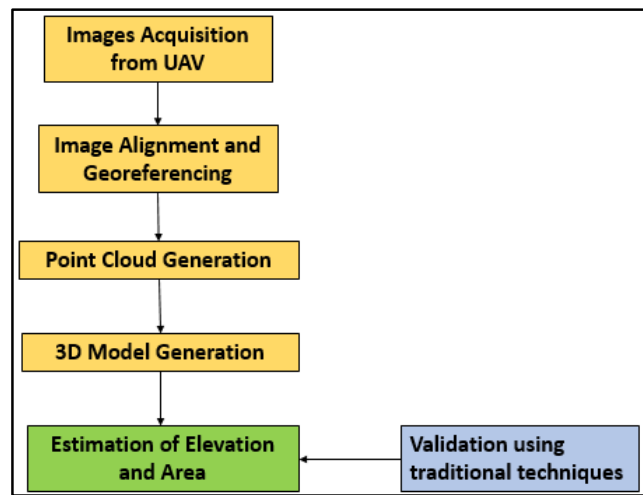

Figure. 4. Methodology

The main objective of this study is to explore UAV applications in terms of 3D modelling, visualization and parameter calculations. Main emphasis is given on the measurement of the height and area calculations. Methodology adopted for the study is shown as Fig.4. UAV model, DJI Inspire has been used for acquiring images of the study area. $12 \mathrm{MP}$ Zenmuse $\mathrm{X} 3$ gimbal camera is used for the purpose. Table 1 shows the UAV parameters. The pathway for flying the UAV mainly depends on the flying height, percentage of overlap (side and forward) of images acquired, tilt angle of camera. Fig. 5 shows the flight pathway of the study area.

\begin{tabular}{|l|c|}
\hline Name & DJI INSPIRE 1 \\
Weight & $3.06 \mathrm{~kg}$ \\
GPS Accuracy & $0.5 \mathrm{~m}$ (vertical), $2.5 \mathrm{~m}$ (Horizontal) \\
Maximum tilt angle & $35^{\circ}$ \\
Maximum flight time & 18 minutes \\
Camera resolution & $12 \mathrm{MP}$ \\
Focal length & 2.8 \\
Field of View (FOV) & $94^{\circ}$ \\
Shutter speed & $1 / 8000$ seconds \\
\hline
\end{tabular}

Table 1. UAV Parameters

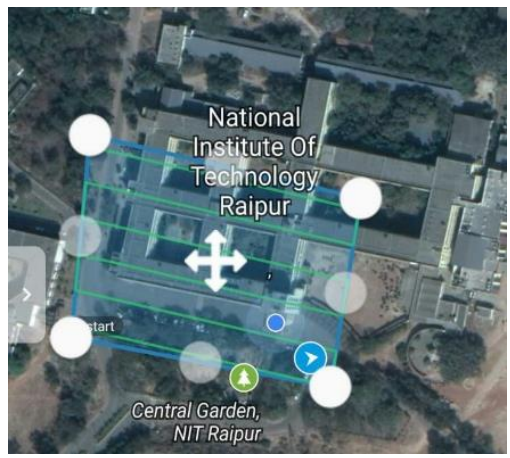

Figure.5. Flight pathway 
UAV was flown at an altitude of 222 feet from ground level. To attain the stereo pairs, side and forward overlap has been kept at $85 \%$. A total of 181 images were obtained for the 4 acres of study area. The images were processes in Photoscan software which works on Structure from Motion (SFM) algorithm which is a low-cost photogrammetric technique for high-resolution topographic reconstructions. It works on the principle of the stereoscopic photogrammetry. This method is most suitable to sets of images having degree of overlap that takes into account the 3D structure of the scene (Szeliski, 2010 and Westoby et.al 2012). The elevation and area from the model are validated with the values obtained from standard surveying instrument like theodolite and Electronic Distance Measurement (EDM).

\section{RESULTS AND DISCUSSION}

As the number of images is higher, it was desirable to divide the whole project into chunk (sub-parts). It allows the improvement in image processing. Image alignment was done automatically by the software. The Ground Sample Distance (GSD) was found to be $3.75 \mathrm{~cm}$ per pixel. High quality point cloud of 32480724 points has been processed from all 181 images. Fig.6 shows the point cloud of the UAV acquired images.

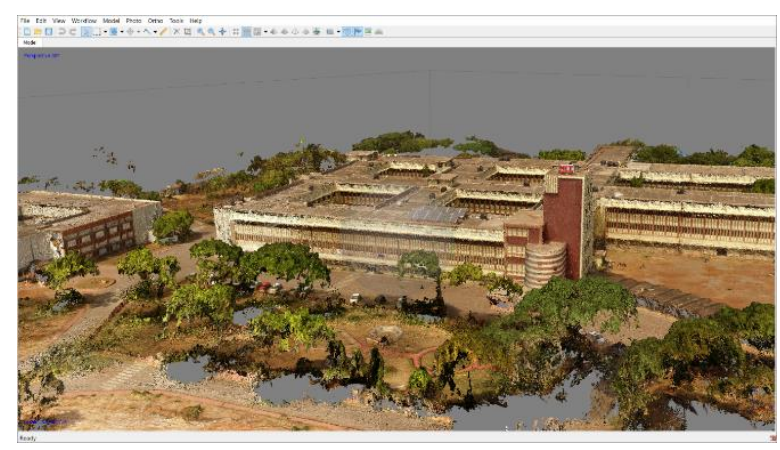

Fig.6. Point cloud of NIT Raipur

The elevations of six different points of NIT Raipur main building were calculated. The average accuracy obtained for elevation points and area is $97.99 \%$ and $97.75 \%$. Fig.7 and Fig.8 shows the 3D model of the building with the points of elevation and area are calculated respectively.

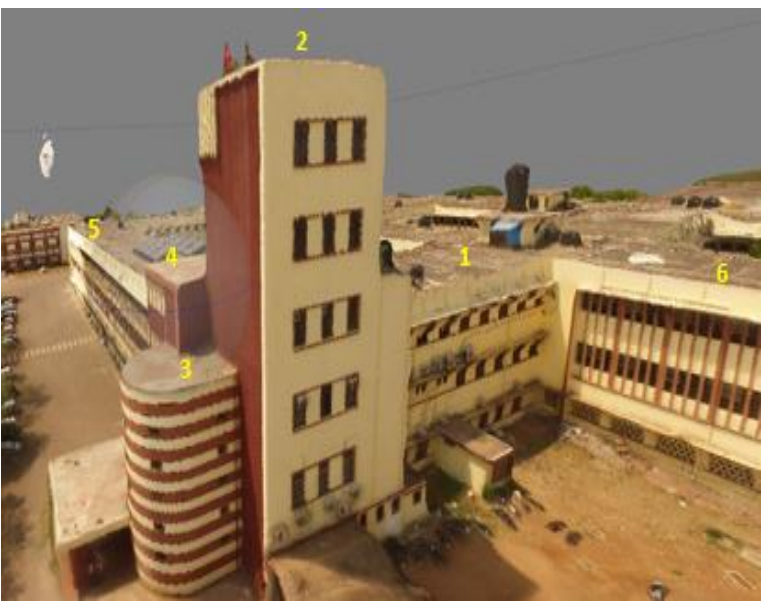

Figure.7. 3D model with sample points for elevation
Table 2 depicts the comparison of elevation values obtained from standard techniques. Table 3 represents the area calculated using the model and standard measurement.

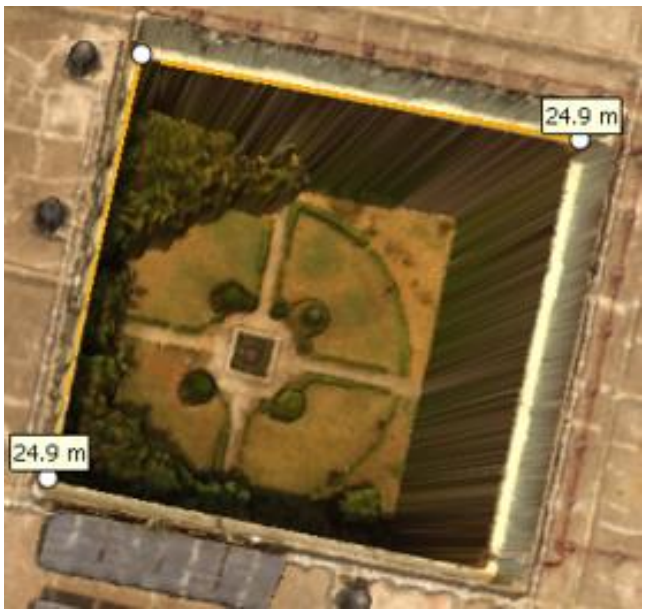

Figure.8. Dimension measurement for area

\begin{tabular}{|c|c|c|c|c|c|c|}
\hline $\begin{array}{l}\text { S. } \\
\text { No }\end{array}$ & $\begin{array}{l}\text { Poin } \\
t\end{array}$ & $\begin{array}{l}\text { Ele } \\
\text { vati } \\
\text { on } \\
\text { Obt } \\
\text { aine } \\
\text { d } \\
\text { fro } \\
\text { m } \\
\text { mo } \\
\text { del } \\
\text { (m) }\end{array}$ & $\begin{array}{l}\text { Elevat } \\
\text { ion } \\
\text { obtain } \\
\text { ed } \\
\text { from } \\
\text { Theod } \\
\text { olite } \\
\text { (m) }\end{array}$ & $\begin{array}{l}\text { Eleva } \\
\text { tion } \\
\text { obtai } \\
\text { ned } \\
\text { from } \\
\text { EDM } \\
\text { (m) }\end{array}$ & $\begin{array}{c}\text { Mod } \\
\text { el } \\
\text { Vs } \\
\text { EDM } \\
\text { Accu } \\
\text { racy }\end{array}$ & $\begin{array}{c}\text { Mode } \\
1 \\
\text { Vs } \\
\text { Theod } \\
\text { olite } \\
\text { Accur } \\
\text { acy }\end{array}$ \\
\hline 1 & $\begin{array}{c}\text { Poin } \\
\text { t } 1\end{array}$ & $\begin{array}{c}14 . \\
68\end{array}$ & 14.24 & 14.30 & $\begin{array}{c}97.41 \\
\%\end{array}$ & $97 \%$ \\
\hline 2 & $\begin{array}{c}\text { Poin } \\
\text { t } 2\end{array}$ & $\begin{array}{l}27 . \\
43\end{array}$ & 27.36 & 26.90 & $\begin{array}{c}99.74 \\
\%\end{array}$ & $\begin{array}{c}97.58 \\
\%\end{array}$ \\
\hline 3 & $\begin{array}{c}\text { Poin } \\
\text { t } 3\end{array}$ & $\begin{array}{l}11 . \\
98\end{array}$ & 11.77 & 11.75 & $\begin{array}{c}98.08 \\
\%\end{array}$ & $\begin{array}{c}98.24 \\
\%\end{array}$ \\
\hline 4 & $\begin{array}{c}\text { Poin } \\
\text { t } 4\end{array}$ & $\begin{array}{l}17 . \\
85\end{array}$ & 17.60 & 17.48 & $\begin{array}{c}97.92 \\
\%\end{array}$ & $\begin{array}{c}98.59 \\
\%\end{array}$ \\
\hline 5 & $\begin{array}{c}\text { Poin } \\
\text { t } 5\end{array}$ & $\begin{array}{c}14 . \\
68\end{array}$ & 14.24 & 14.30 & $\begin{array}{c}97.41 \\
\%\end{array}$ & $97 \%$ \\
\hline 6 & $\begin{array}{c}\text { Poin } \\
\text { t } 6\end{array}$ & $\begin{array}{c}14 . \\
68\end{array}$ & 14.24 & 14.30 & $\begin{array}{c}97.41 \\
\%\end{array}$ & $97 \%$ \\
\hline
\end{tabular}

Table 2. Comparison of elevation values obtained from different techniques

\begin{tabular}{|c|c|c|c|}
\hline Area Measurement & $\begin{array}{c}\text { Length } \\
(\mathrm{m})\end{array}$ & $\begin{array}{c}\text { Width } \\
(\mathrm{m})\end{array}$ & $\begin{array}{c}\text { Area } \\
\left(\mathrm{m}^{2}\right)\end{array}$ \\
\hline $\begin{array}{c}\text { From measuring } \\
\text { tape }\end{array}$ & 25.23 & 25.14 & 634.28 \\
$\begin{array}{c}\text { From model } \\
\text { Accuracy }\end{array}$ & 24.9 & 24.9 & 620.01 \\
\hline
\end{tabular}

Table 3. Comparison of area obtained from different techniques 


\section{CONCLUSION}

In this study, UAV is deployed for accruing high resolution images for generation of 3D models. The results are compared with traditional methods for validation. The average accuracy obtained for elevation for elevation points and area is $97.99 \%$ and $97.75 \%$. The study proves that UAV based surveying is an economical alternative in terms of money, time and resources, when compared to the classical aerial photogrammetry methods.

\section{REFERENCES}

Alkaabi, Khaula \& Abuelgasim, Abdelgadir. (2017). Applications of Unmanned Aerial Vehicle (UAV) Technology for Research and Education in UAE. International Journal of Social Sciences Arts and Humanities. 5. 2321-4147.

Brown D C (1976) The bundle adjustment - progress and prospects. In: International Archives of Photogrammetry, 21(3).

Colomina I, Blázquez M, Molina P, Parés M.E, Wis M (2008) Towards a new paradigm for high-resolution low-cost photogrammetry and remote sensing. Int. Archives of Photogrammetry, Remote Sensing and Spatial Information Sciences, Beijing, China, 37 (B1): 1201-1206.

Eisenbeiss H (2009) UAV photogrammetry. Dissertation ETH No. 18515, Institute of Geodesy and Photogrammetry, ETH Zurich, Switzerland, Mitteilungen 105.

Gruen A, Beyer H A (2001) System calibration through selfcalibration. Calibration and Orientation of Cameras in Computer Vision, Gruen and Huang (Eds.), Springer Series in Information Sciences, 34: 163-194.

Neitzel F, Klonowski J (2011). Mobile 3D mapping with lowcost UAV system. Int. Archives of Photogrammetry, Remote Sensing and Spatial Information Sciences, Zurich, Switzerland, $38(1 / \mathrm{C} 22)$

Pfeifer N, Glira P, Briese C (2012) Direct georeferencing with on board navigation components of light weight UAV platforms. Int. Archives of Photogrammetry, Remote Sensing and Spatial Information Sciences, Melbourne, Australia,39(7).

$\begin{array}{lcl}\text { Photoscan Manual. Available } & \text { online: } \\ \text { http//www.agisoft.com/pdf/photoscan pro_1_1_en.pdf. } & \end{array}$

Sanna A, Pralio B (2005) Simulation and control of mini UAVs. Proc. 5th WSEAS Int. Conference on Simulation, Modelling and Optimization, 135-141.

Szeliski, R. Computer Vision: Algorithms and Applications; Springer: Berlin, Germany, 2010.

Triggs W, McLauchlan P, Hartley R, Fitzgibbon A (2000) Bundle adjustment - A modern synthesis. Eds W. Triggs, A. Zisserman, and R Szeliski Vision Algorithms: Theory and Practice, LNCS, Springer Verlag, pp. 298-375.

Von Blyenburg P (1999) UAVs-Current Situation and Considerations for the Way Forward. RTO-AVT Course on Development and Operation of UAVs for Military and Civil Applications, 1999.

Westoby,M.J.; Brasington, J.;Glasser,N.F.;Hambrey,M.J.; Reynolds, J.M. 'Structure-from-Motion' photogrammetry: A low-cost, effective tool for geoscience applications. Geomorphology 2012, 179, 300-314. [CrossRef]

Zhou G (2009) Near real-time orthorectification and mosaic of small UAV video flow for time-critical event response. IEEE Trans. Geoscience and Remote Sensing, 47(3): 739-747. 